\title{
Prevalencia y distribución de los principales agentes etiológicos que afectan los langostinos silvestres en Tumbes, Perú
}

\section{Prevalence and distribution of the principal etiologic agents that affecting wild shrimps from Tumbes, Peru}

\author{
Rubén Alfaro Aguilera ${ }^{1 *}$, Mervin Guevara Torres ${ }^{1}$ Isaías Gonzales Chávez
}

1 Laboratorio de Sanidad Acuícola Instituto del Mar del Perú- IMARPE, Sede Tumbes, Panamericana Norte Km. 1249, Zorritos, Tumbes, Perú. E-mail Rubén Alfaro: ralfaro@imarpe.gob.pe
Presentado: $\quad 03 / 09 / 2010$ Publicado online:

\section{Resumen}

Se determinó la prevalencia y distribución de diferentes agentes patógenos en langostinos silvestres, en la zona de esteros de la Región Tumbes - Perú, entre marzo y diciembre de 2009. Los canales de marea considerados en este estudio fueron: Boca del Río Tumbes, El Alcalde, Jelí, El Bendito, Envidia, Soledad y Algarrobo. Se colectó un total de 1926 langostinos entre juveniles y pre-adultos de las especies Litopenaeus vannamei, $L$. stylirostris y Farfantepenaeus californiensis. Utilizando la técnica de la PCR, se detectó la presencia de los patógenos NHPB $(0,62 \%)$, IHHNV $(0,31 \%)$, BP $(1,61 \%)$ y WSV $(2,75 \%)$; no se encontró infección por TSV. Las tres especies en estudio fueron positivas a WSV y BP, presentándose la mayor prevalencia de infección por WSV $(2,98 \%)$ en la especie $L$. stylirostris y por BP $(2,66 \%)$ en $L$. vannamei. La NHPB fue detectada en las especies $L$. vannamei y $L$. stylirostris con $0,77 \%$ y $0,43 \%$ de prevalencia respectivamente. Se obtuvo una prevalencia de $0,52 \%$ para IHHNV en $L$. vannamei. Las más altas prevalencias de las infecciones por WSV, BP, NHPB e IHHNV se registraron en los canales de marea El Alcalde (10,79\%), Algarrobo (4,51\%), Envidia $(2,26 \%)$ y Jelí $(5,05 \%)$. Los datos señalan la presencia constante de diversos patógenos virales y bacterianos en diferentes especies de peneidos y su amplia distribución a lo largo del litoral tumbesino, lo que constituye un riesgo potencial para el desarrollo de la acuicultura en la región, y podría afectar las poblaciones naturales de langostinos.

Palabras Clave: Prevalencia, WSV, IHHNV, BP, enfermedades langostinos.

\section{Abstract}

Prevalence and distribution of different pathogens of wild shrimp in the tidal channels of the Region Tumbes Peru, during March to December 2009. The tidal channels considered in this study were: Boca del Rio Tumbes, El Alcalde, Jelí, El Bendito, Envidia, Soledad and Algarrobo. We collected a total of 1926 shrimps between juvenile and pre-adults of the species Litopenaeus vannamei, L. stylirostris y Farfantepenaeus californiensis. Using the PCR technique, detected the presence of pathogens NHPB $(0.62 \%)$, IHHNV $(0.31 \%)$, BP $(1.61 \%)$ and WSV (2.75\%); no infection was found by TSV. The three species studied were positive for WSV and BP showed the highest prevalence of WSV infection $(2.98 \%)$ in the species $L$. stylirostris and BP $(2.66 \%)$ in $L$. vannamei. The NHPB was detected in the species $L$. vannamei, $L$. stylirostris to $0.77 \%$ and $0.43 \%$ prevalence respectively. There was a prevalence of $0.52 \%$ for IHHNV in $L$. vannamei. The highest prevalence of infections WSV, BP, NHPB and IHHNV were recorded in the tidal channels El Alcalde (10.79\%), Algarrobo (4.51\%), Envidia $(2.26 \%)$ and Jeli $(5.05 \%)$ respectively. Data showed that the constant presence of various pathogens in different penaeid species and their wide distribution along the coast Tumbes, which could produce an impact on wild stocks of shrimp and being a potential risk for development of aquaculture in the region.

Keywords: Prevalence, WSV, IHHNV, BP, shrimp diseases.

\section{Introducción}

La actividad de cultivo de langostinos o camarones peneidos en el Perú está concentrada en la Región Tumbes, en ambientes aledaños al ecosistema de manglares y esteros. Se ha demostrado que muchos patógenos que causan enfermedades en los sistemas de cultivo provienen de poblaciones naturales, de las mismas especies o de especies emparentadas a las cultivadas. Así mismo, las enfermedades de las especies en cultivo, también pueden afectar a las poblaciones naturales poniendo en riesgo su estatus sanitario (Raynard et al. 2007).

Los langostinos peneidos tanto silvestres como de cultivo, son afectados por diversos agentes patógenos, principalmente de naturaleza viral y bacteriana. Las infecciones virales son consideradas las más importantes desde el punto de vista epidemiológico, causando pérdidas significativas en la producción de langostinos en todo el mundo.

Una de las enfermedades de peneidos más letales, es la producida por el virus de la mancha blanca (white spot syndrome virus, WSV o WSSV), que además afecta varias especies de crustáceos decápodos de ambientes marinos, estuarinos y de agua dulce (Lo et al. 1996, Corbel et al. 2001, Chakraborty et al. 2002, Sánchez-Martínez et al. 2007). Esta enfermedad puede producir mortalidades acumulativas en estanques de cultivo del 80 al 100\% después de 7 a 10 días de la infección (Nakano et al. 1994).

El Baculovirus penaei (BP), es considerado enzoótico en peneidos silvestres del continente Americano y Hawai. Se tienen registros de su presencia en langostinos silvestres y de cultivo de varias regiones de la costa del Pacífico, desde Perú a México y en países como Brasil, Cuba y el sureste de los Estados Unidos (OIE 2006, Lightner 1996, Fajer et al. 1998). Son susceptibles a la infección por BP algunas especies de los géneros Litopenaeus, Farfantepenaeus y Penaeus (Lightner 1996); ha producido elevadas mortalidades en estadios de larvas y postlarvas, así como reducción de la alimentación y bajas tasas de crecimiento (Morales \& Cuellar-Anjel 2008).

Otro agente patógeno que infecta a la mayoría de las especies de peneidos, es el virus de la necrosis hipodérmica y hematopoyética infecciosa (IHHNV, Infectious hypodermal and haematopoietic necrosis virus), que produce infecciones graves en juveniles y pre-adultos de L. stylirostris; causando mortalidades masivas en esta especie (OIE 2006). En L. vannamei, la infec- 


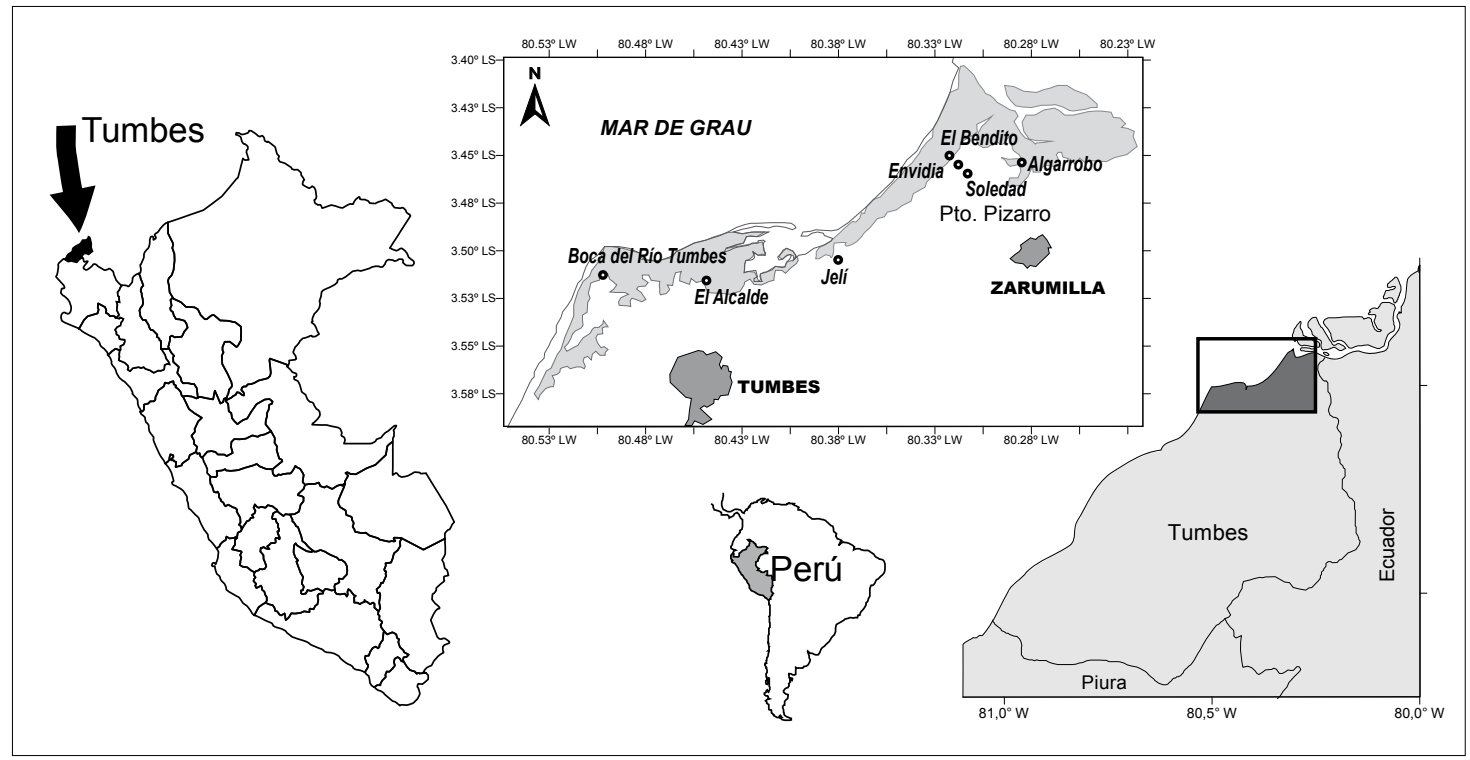

Figura 1. Ubicación geográfica de los canales de marea en estudio, en el ecosistema manglar de la Región Tumbes, Perú.

ción por IHHNV es de tipo crónico, produciendo deformidad cuticular y crecimiento reducido e irregular (Lightner 1996). Este virus se encuentra distribuido a nivel mundial, tanto en langostinos silvestres como de cultivo (Morales \& Cuellar-Anjel 2008). En el hemisferio occidental, ha sido descrito desde Perú a México, incluyendo Hawai, la Polinesia Francesa y Nueva Caledonia; además, ha sido reportado en varios países de Asia y en el medio oriente (OIE 2006).

El virus del síndrome de Taura (TSV), apareció inicialmente en Ecuador en el año 1992, y ahora se encuentra distribuido en muchos países de América Central, Sudamérica y Hawai (Lightner 1996). También, ha sido registrado hace algunos años en Taiwán y China, siendo el origen de la infección la especie L. vannamei procedente del hemisferio occidental (Lien et al. 2002). Se han documentado infecciones en poblaciones silvestres de L. vannamei, L. stylirostris y L. setiferus, siendo en los estadios posteriores a postlarvas 12 y juveniles de langostinos, las infecciones más severas (Morales \& Cuellar-Anjel 2008). La enfermedad producida por TSV presenta tres fases bien definidas, una fase aguda en el cual se produce la mayor mortandad de langostinos; la fase de transición o recuperación y la fase crónica, donde los langostinos infectados no muestran síntomas de la enfermedad.

Entre los patógenos bacterianos de importancia, la NHPB (bacteria de la necrosis del hepatopáncreas) produce una enfermedad severa, con mortalidades entre 20 a $90 \%$ en los sistemas de cultivo (Loy et al. 1996). Esta bacteria ha sido reportada solo en peneidos de América y ha sido reconocida en diferentes especies, entre ellas: L. vannamei, L. aztecus, L. setiferus, L. stylirostris y $F$. californiensis.

Los patógenos seleccionados y evaluados en esta investigación, tienen características comunes tales como generar pérdidas significativas de producción, afectar a poblaciones naturales de crustáceos acuáticos y presentar rápida propagación en poblaciones de cultivo.

En el presente trabajo, se estudió la prevalencia y distribución de patógenos virales y bacterianos en peneidos silvestres en ambientes naturales aledaños a las zonas de cultivo de la Región Tumbes.

\section{Material y métodos}

Área de estudio.- Se evaluaron seis canales de marea del ecosistema de manglar de la Región Tumbes (Fig. 1), ubicados en las provincias de Tumbes y Zarumilla: Boca del río Tumbes (3³0'28,92”S; 80²9'49,86”W), El Alcalde (3॰30'56,22"S; 80²6’36,12”W), Jelí (3²9’43,98”S; 80²2’28,98”W), El Bendito (3०26'59,76"S; 80¹9'3,6”W), Soledad (3²7'31,86"S; 80¹8'30,48”W) y Algarrobo (3²8'13,68”'S; 80¹7'53,34”W). Debido a la poca captura de langostinos para completar la muestra mínima requerida, a partir de junio hasta diciembre se incorporó al estudio el canal de marea Envidia (3०27’18,36"S; 80¹8'45,42”W). Estos canales de marea, además de ser los más accesibles, se encuentran aledańos a las zonas de cultivo de langostinos y sirven como zona de captación de agua y descarga de efluentes por las empresas langostineras, lo que los hace de utilidad para este estudio.

Colecta de muestras.- Entre los meses de marzo a diciembre de 2009, se capturaron juveniles y pre-adultos de langostinos silvestres con periodicidad quincenal. La captura se realizó mediante lances de atarraya, hasta completar un mínimo de 20 ejemplares por canal de marea. Las muestras de langostinos obtenidas fueron etiquetadas y transportadas en hielo al Laboratorio de Sanidad Acuícola de la Sede IMARPE Tumbes. En el laboratorio, se tomaron datos individuales de los langostinos como peso, talla y alguna característica adicional externa de interés (flacidez, coloración rojiza, músculo blanco, deformidad o necrosis cuticular). Las branquias y hepatopáncreas fueron extraídos y conservados en etanol al 96\% y almacenadas a -20 ${ }^{\circ} \mathrm{C}$, hasta su análisis respectivo.

Extracción de ácidos nucleicos.- Las extracciones de ADN se realizaron por individuo, utilizando el método estándar CTAB-DTAB (Gustincich et al. 1991) con modificaciones. En un microtubo de $1,5 \mathrm{~mL}$ se colocó $25 \mathrm{mg}$ del tejido branquial y se agregó $600 \mu \mathrm{L}$ de solución DTAB (dodeciltrimetilamonio bromuro 8\%, $\mathrm{NaCl}$ 1,5 M, Tris $\mathrm{HCl} 100 \mathrm{mM}$ pH 8,8 y EDTA $50 \mathrm{mM}$ ), a los tejidos de hepatopáncreas se añadió además 100 $\mu \mathrm{L}$ de EDTA $500 \mathrm{mM}$. Con la ayuda de un micromacerador de plástico se homogenizó el tejido, la mezcla fue incubada a $75^{\circ} \mathrm{C}$ por $5 \mathrm{~min}$, después de lo cual se agregó $700 \mu \mathrm{L}$ de 
Tabla 1. Relación de cebadores específicos para cada patógeno evaluado y productos de amplificación de la PCR.

\begin{tabular}{|c|c|c|c|c|c|}
\hline Patógeno & & Cebador & Secuencia & Producto & Referencia \\
\hline \multirow{2}{*}{ NHPB } & & pf-1 & 5’ ACG TTG GAG GTT CGT CCT TCA G 3' & \multirow[t]{2}{*}{$441 \mathrm{pb}$} & \multirow[t]{2}{*}{ Loy et al. 1996} \\
\hline & & pr-2 & $5^{\prime}$ TCA CCC CCT TGC TTC TCA TTG T 3' & & \\
\hline \multirow{2}{*}{ IHHNV } & & $77012 \mathrm{~F}$ & 5’ ATC GGT GCA CTA CTC GGA 3' & \multirow[t]{2}{*}{$356 \mathrm{pb}$} & \multirow[t]{2}{*}{ OIE 2006} \\
\hline & & $77353 R$ & $5^{\prime}$ TCG TAC TGG CTG TTC ATC $3^{\prime}$ & & \\
\hline \multirow{2}{*}{ BP } & & BPA & 5' GAT CTG CAA GAG GAC AAA CC 3' & \multirow[t]{2}{*}{$560 \mathrm{pb}$} & \multirow[t]{2}{*}{ OIE 2006} \\
\hline & & $\mathrm{BPB}$ & 5’ ATC GCT AAG CTC TGG CAT CC $3^{\prime}$ & & \\
\hline \multirow{4}{*}{ WSV } & \multirow{2}{*}{$1 \mathrm{rx}$} & $146 \mathrm{~F} 1$ & 5’ ACT ACT AAC TTC AGC CTA TCT AG 3' & \multirow[t]{2}{*}{$1.447 \mathrm{pb}$} & \multirow[t]{2}{*}{ OIE 2006} \\
\hline & & 146R1 & $5^{\prime}$ TAA TGC GGG TGT AAT GTT CTT ACG A 3' & & \\
\hline & \multirow{2}{*}{$2 \mathrm{rx}$} & $146 \mathrm{~F} 2$ & 5' GTA ACT GCC CCT TCC ATC TCC A 3' & \multirow[t]{2}{*}{$941 \mathrm{pb}$} & \multirow[t]{2}{*}{ OIE 2006} \\
\hline & & $146 \mathrm{R} 2$ & $5^{\prime}$ TAC GGC AGC TGC TGC ACC TTG T 3' & & \\
\hline \multirow{2}{*}{ TSV } & & $9992 \mathrm{~F}$ & 5' AAG TAG ACA GCC GCG CTT 3' & \multirow[t]{2}{*}{$231 \mathrm{pb}$} & \multirow[t]{2}{*}{ OIE 2006} \\
\hline & & 9195R & 5' TCA ATG AGA GCT TGG TCC 3' & & \\
\hline
\end{tabular}

cloroformo HPLC, se mezcló en vortex y se centrifugó en una microcentrífuga a $12000 \mathrm{rpm}$ por $5 \mathrm{~min}$. El sobrenadante $(250$ $\mu \mathrm{L})$ fue transferido a otro microtubo de $1,5 \mathrm{~mL}$ que contenía $100 \mu \mathrm{L}$ de solución CTAB (5\% cetiltrimetilamonio bromuro, $0,4 \mathrm{M} \mathrm{NaCl}$ ) y $900 \mu \mathrm{L}$ de agua destilada autoclavada; se mezcló, incubó a $75{ }^{\circ} \mathrm{C}$ por 5 min y centrifugó a $12000 \mathrm{rpm}$ por 10 min; el sobrenadante fue descartado y el pellet resuspendido en $150 \mu \mathrm{L}$ de solución disolvente $(\mathrm{NaCl} 1,2 \mathrm{M})$ se incubó a $75^{\circ} \mathrm{C}$ por 5 min y se centrifugó a $12000 \mathrm{rpm}$ por $5 \mathrm{~min}$. Finalmente la solución fue transferida a un nuevo microtubo con $300 \mu \mathrm{L}$ de etanol 95\%, se mezcló y centrifugó nuevamente a 12000 rpm por 5 min, el pellet fue lavado con etanol al 75\%, secado por 10 min y resuspendido con agua ultrapura.

Las extracciones de ARN se realizaron por grupos de 5 ejemplares, con el kit de extracción de ARN del Laboratorio IQ-2000 ${ }^{\mathrm{TM}}$ (GeneReach Biotechnology Corp, Taiwan) siguiendo las indicaciones del fabricante.

Análisis por PCR.- Los cebadores específicos para los diferentes patógenos en estudio y sus productos de amplificación, se muestran en la Tabla 1. Las muestras fueron analizadas mediante la técnica de PCR simple para el descarte de la NHPB. Las reacciones se realizaron en mezclas de $20 \mu \mathrm{L}$, con $2 \mu \mathrm{L}$ de buffer Taq 10X (100 mM Tris- $\mathrm{HCl}$ pH 8,8, $500 \mathrm{mM} \mathrm{KCl} \mathrm{y} \mathrm{0,8 \%} \mathrm{de}$ Nonidet P-40), 1,5 mM de $\mathrm{MgCl}_{2}, 0,125 \mathrm{mM}$ de cada dNTPs, 1,25 U de Taq ADN polimerasa recombinante (Fermentas Life Sciences, Lituania), 10 pmol de cada cebador y $2 \mu \mathrm{L}$ de ADN extraído. El perfil de la PCR se realizó en un termociclador (9800 Fast Thermal Cycler, Applied Biosystems, USA), este consta de 35 ciclos de $94^{\circ} \mathrm{C}$ por $30 \mathrm{~s}, 58^{\circ} \mathrm{C}$ por $30 \mathrm{~s}, 72^{\circ} \mathrm{C}$ por $1 \mathrm{~min}$ y una extensión final a $72{ }^{\circ} \mathrm{C}$ por $5 \mathrm{~min}$.

Para la detección del IHHNV, se preparó un volumen de reacción final de $20 \mu \mathrm{L}$, constituida por $2 \mu \mathrm{L}$ de buffer Taq 10X, 2 mM de $\mathrm{MgCl}_{2}$, 0,2 mM de cada dNTPs, 1,25 U de Taq ADN polimerasa recombinante, $150 \mathrm{ng}$ de cada cebador y $2 \mu \mathrm{L}$ de ADN extraído. El programa de la PCR (termociclador 9800 Fast Thermal Cycler, Applied Biosystems, USA) consta de un ciclo a $94^{\circ} \mathrm{C}$ por $5 \mathrm{~min}, 35$ ciclos de $95^{\circ} \mathrm{C}$ por $30 \mathrm{~s}, 55^{\circ} \mathrm{C}$ por $30 \mathrm{~s}, 72^{\circ} \mathrm{C}$ por $1 \mathrm{~min}$ y una extensión final a $72^{\circ} \mathrm{C}$ por $5 \mathrm{~min}$.

El Baculovirus penaei fue analizado utilizando un volumen de reacción de $20 \mu \mathrm{L}$, constituido por $2 \mu \mathrm{L}$ de buffer Taq $10 \mathrm{X}$, 1,5 mM de $\mathrm{MgCl}_{2}, 0,2 \mathrm{mM}$ de cada dNTPs, $1 \mathrm{U}$ de Taq ADN polimerasa recombinante, $5 \mathrm{pmol}$ de cada cebador y $2 \mu \mathrm{L}$ de
ADN extraído. La PCR (termociclador 9800 Fast Thermal Cycler, Applied Biosystems, USA) se realizó con un ciclo a 95 ${ }^{\circ} \mathrm{C}$ por $5 \mathrm{~min}, 30$ ciclos de $94^{\circ} \mathrm{C}$ por $30 \mathrm{~s}, 58^{\circ} \mathrm{C}$ por $45 \mathrm{~s}, 72$ ${ }^{\circ} \mathrm{C}$ por $45 \mathrm{~s}$ y una extensión final a $72^{\circ} \mathrm{C}$ por $5 \mathrm{~min}$.

Se utilizó nested PCR para detección del WSV, siendo 50 $\mu \mathrm{L}$ el volumen final de cada reacción, constituido por $5 \mu \mathrm{L}$ de buffer Taq 10X, 1,5 mM de $\mathrm{MgCl}_{2}, 0,2 \mathrm{mM}$ de cada dNTPs, $1 \mathrm{U}$ de Taq ADN polimerasa recombinante, $10 \mathrm{pmol}$ de cada cebador y $1 \mu \mathrm{L}$ de ADN extraído. La PCR fue realizada en un termociclador (Thermolyne Amplitron II, USA), el perfil de amplificación consta de un ciclo de $94^{\circ} \mathrm{C}$ por $5 \mathrm{~min}$, seguido de 30 ciclos de $94^{\circ} \mathrm{C}$ por 30 segundos, $52^{\circ} \mathrm{C}$ por 30 segundos y 72 ${ }^{\circ} \mathrm{C}$ por 45 segundos y una extensión final a $72{ }^{\circ} \mathrm{C}$ por 5 minutos.

La detección del TSV se realizó con RT-PCR, la síntesis del ADN complementario (ADNc), se preparó siguiendo el protocolo descrito por Fermentas Life Sciences (Lituania), utilizando para este fin 20 pmol de cebadores específicos y $2 \mu \mathrm{L}$ de ARN extraído en un volumen final de $11 \mu \mathrm{L}$ por cada microtubo de reacción. Se procedió a incubar a $70{ }^{\circ} \mathrm{C}$ por 5 min y posteriormente se agregó una mezcla de $20 \mu \mathrm{L}$ con los siguientes componentes: $4 \mu \mathrm{L}$ de buffer $5 \mathrm{X}(250 \mathrm{mM}$ Tris- $\mathrm{HCl} \mathrm{pH} 8,3,250 \mathrm{mM} \mathrm{KCl}$, $20 \mathrm{mM} \mathrm{MgCl}$, $50 \mathrm{mM}$ DTT), 0,5 U de inhibidor de RNasa (Fermentas), $200 \mathrm{U}$ de enzima RT M-MuLV (Fermentas), 1 mM de cada dNTPs y 13,7 $\mu \mathrm{L}$ de agua ultrapura.

La RT-PCR se efectuó mediante un ciclo a $42{ }^{\circ} \mathrm{C}$ por 60 min y un ciclo a $70{ }^{\circ} \mathrm{C}$ por $10 \mathrm{~min}$ (termociclador 9800 Fast Thermal Cycler, Applied Biosystems, USA). La PCR se realizó en un volumen final de $20 \mu \mathrm{L}$, utilizándose $2 \mu \mathrm{L}$ de buffer Taq 10X, 2,5 mM de $\mathrm{MgCl}_{2}$, 0,2 mM de cada dNTPs, 1,25 U de Taq ADN polimerasa (Fermentas), 10 pmol de cada cebador y $2 \mu \mathrm{L}$ de ADNc. El programa de amplificación constó de un ciclo a $94^{\circ} \mathrm{C}$ por $5 \mathrm{~min}$, seguido de 30 ciclos de $94^{\circ} \mathrm{C}$ por 30 segundos, $60{ }^{\circ} \mathrm{C}$ por 30 segundos y $72{ }^{\circ} \mathrm{C}$ por 45 segundos y una extensión final a $72{ }^{\circ} \mathrm{C}$ por 5 minutos.

Los productos de amplificación fueron verificados por electroforesis (TAE $1 \mathrm{X}$ ), en geles de agarosa al $1 \%$, teñidos con bromuro de etidio $(0,5 \mathrm{ug} / \mathrm{mL})$ y por electroforesis en TAE $1 X$.

Análisis de datos.- Los datos fueron procesados en el programa Working in Epidemiology (de Blas 2006, http://www. winepi.net/), con un nivel de confianza del 95\%. La distribución de los diferentes patógenos fue procesada en la hoja de cálculo Microsoft Office Excel y en el programa Surfer. 
Tabla 2. Número de ejemplares de langostinos peneidos por especie, capturados en los canales de marea de Tumbes, marzo a diciembre de 2009.

\begin{tabular}{lc}
\hline Especie & Ejemplares capturados \\
\hline Litopenaeus vannamei & 1164 \\
Litopenaeus stylirostris & 704 \\
Farfantepenaeus californiensis & 58 \\
Total & 1926 \\
\hline
\end{tabular}

\section{Resultados}

Prevalencia.- Un total de 1926 langostinos de las especies $L$. vannamei, L. stylirostris y F. californiensis fueron colectados (Tabla 2). La mayoría de especímenes capturados presentaron aparente buen estado de salud y los signos de enfermedad observados en algunos casos fueron coloración rosada del cuerpo, opacidad difusa y lechosa del músculo, expansión de cromatóforos del epitelio cuticular, urópodos rojos, branquias oscuras o necrosis multifocal en cutícula.

Las mayores prevalencias obtenidas, corresponden a los patógenos WSV $(2,75 \%)$ y BP $(1,61 \%)$, sin obtenerse resultados positivos al TSV (Tabla 3). Teniendo en cuenta la población en estudio, se estimaron las prevalencias máximas y mínimas de cada uno de los patógenos enzoóticos de la zona en estudio (Fig. 2).

Se observó que las especies L. vannamei y L. stylirostris son infectados por WSV, BP y NHPB; sólo L. vannamei es infectado por IHHNV. En F. californiensis, se encontró a los virus BP y WSV con valores de prevalencia iguales (1,72\%) (Fig. 3).

Los valores de prevalencia puntual máxima para WSV se encontraron en la última quincena de junio $(10,17 \%)$ y primera quincena de julio $(16,30 \%)$ y los más bajos entre los meses de setiembre a diciembre $(0,00$ a 2,08\%). La NHPB presentó un comportamiento similar al WSV, presentándose brotes de infección por esta bacteria en la época de menores temperaturas (4,62\%). El BP mantiene valores constantes entre los meses de marzo a mayo, pero desde setiembre hasta noviembre se registra su valor más alto de prevalencia $(7,56 \%)$. El IHHNV fue detectado en el mes de setiembre $(0,67 \%)$, y alcanzó su mayor prevalencia en el mes de diciembre con 5,71\% (Fig. 4).

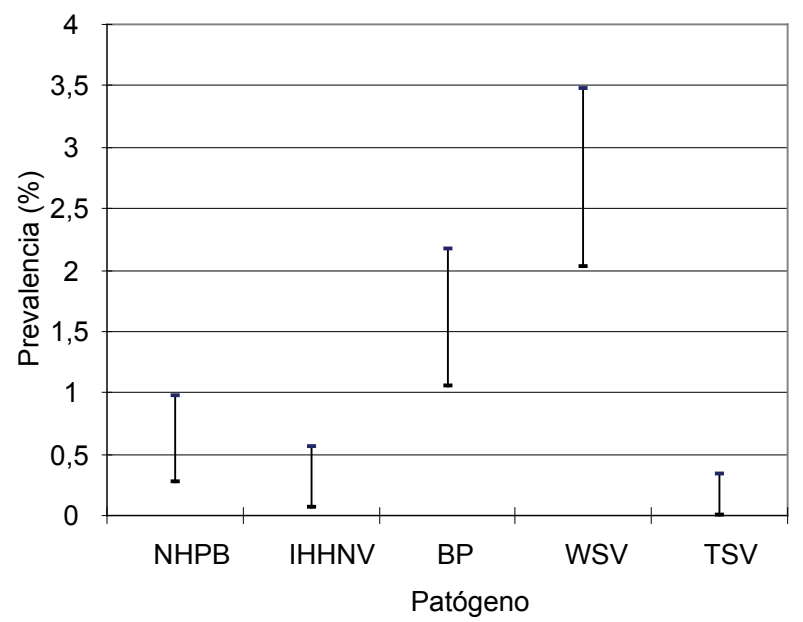

Figura 2. Valores de prevalencia (rangos mínimos y máximos probables) de los principales agentes etiológicos que afectan los langostinos silvestres, Tumbes, 2009
Tabla 3. Prevalencias de infección en langostinos peneidos capturados en los canales de marea de Tumbes, marzo a diciembre de 2009.

\begin{tabular}{lccc}
\hline Patógeno & Tamaño de muestra & Infectados & Prevalencia (\%) \\
\hline NHPB & 1926 & 12 & 0,62 \\
IHHNV & 1926 & 6 & 0,31 \\
BP & 1926 & 31 & 1,61 \\
WSV & 1926 & 53 & 2,75 \\
TSV & 892 & 0 & 0,00 \\
\hline
\end{tabular}

Distribución geográfica.- En los canales de marea en estudio, no se encontraron todos los patógenos evaluados. Se obtuvo muestras positivas al WSV en seis de las zonas monitoreadas, siendo el canal de marea El Alcalde la zona con mayor número de muestras positivas a este patógeno; en el canal de marea Envidia no se registró su presencia (Fig. 5a). El IHHNV se presentó sólo en los canales de marea Jelí (5,05\%) y Envidia (0,38\%) (Fig. $5 \mathrm{~b})$. Las mayores prevalencias para BP fueron obtenidas en los canales de marea El Bendito y Algarrobo con 3,21\% y 4,51\% respectivamente (Fig. 5c).

\section{Discusión}

En el Perú, específicamente la zona noroccidental, donde se desarrolla el cultivo de langostinos, es considerada por muchos investigadores área enzóotica de diversas enfermedades que causan pérdidas significativas en la producción. Los agentes infecciosos de mayor relevancia en el Perú según su aparición en el tiempo comprenden a BP, IHHNV, NHPB, TSV y WSV (Dirección Regional de Pesquería de Tumbes: Estadísticas de producción 2003. Documento interno, datos no publicados). Las especies $L$. vannamei, L. stylirostris y F. californiensis, nativas de los canales de marea o esteros de Tumbes, presentan una elevada susceptibilidad a estos patógenos, sumándose a los factores que afectan negativamente a la posible recuperación de este recurso en áreas naturales.

Durante el tiempo que duró el estudio, se presentaron brotes de infección de los patógenos NHPB, IHHNV, BP y WSV, en las diversas zonas de estudio. El WSV no sólo mostró los valores más altos de prevalencia, si no que se encontró en casi todas las zonas monitoreadas. El WSV tiene la particularidad de presentar un amplio rango de hospederos, considerándose a todos los crustáceos decápodos como especies susceptibles a la

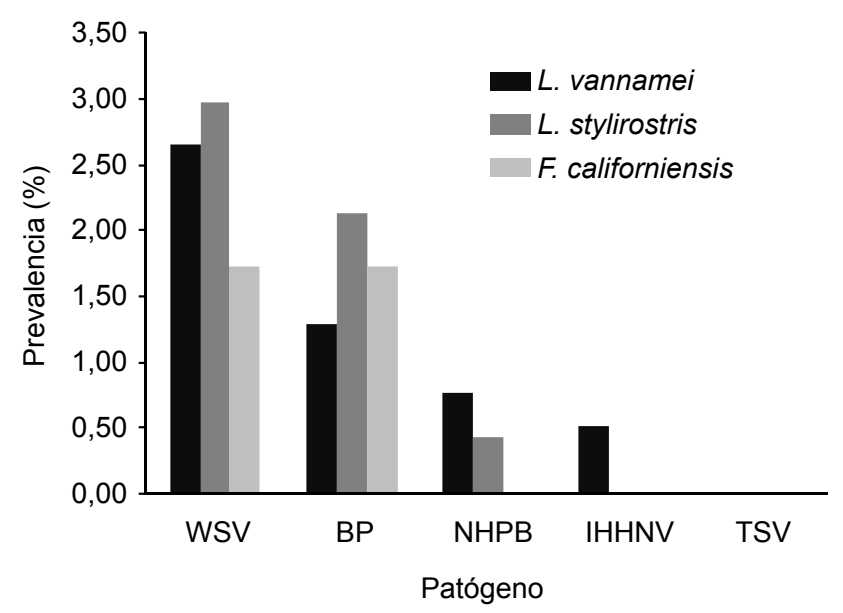

Figura 3. Prevalencia de infección por especie de peneido silvestre capturado en los canales de marea de la Región Tumbes, marzo a diciembre de 2009. 


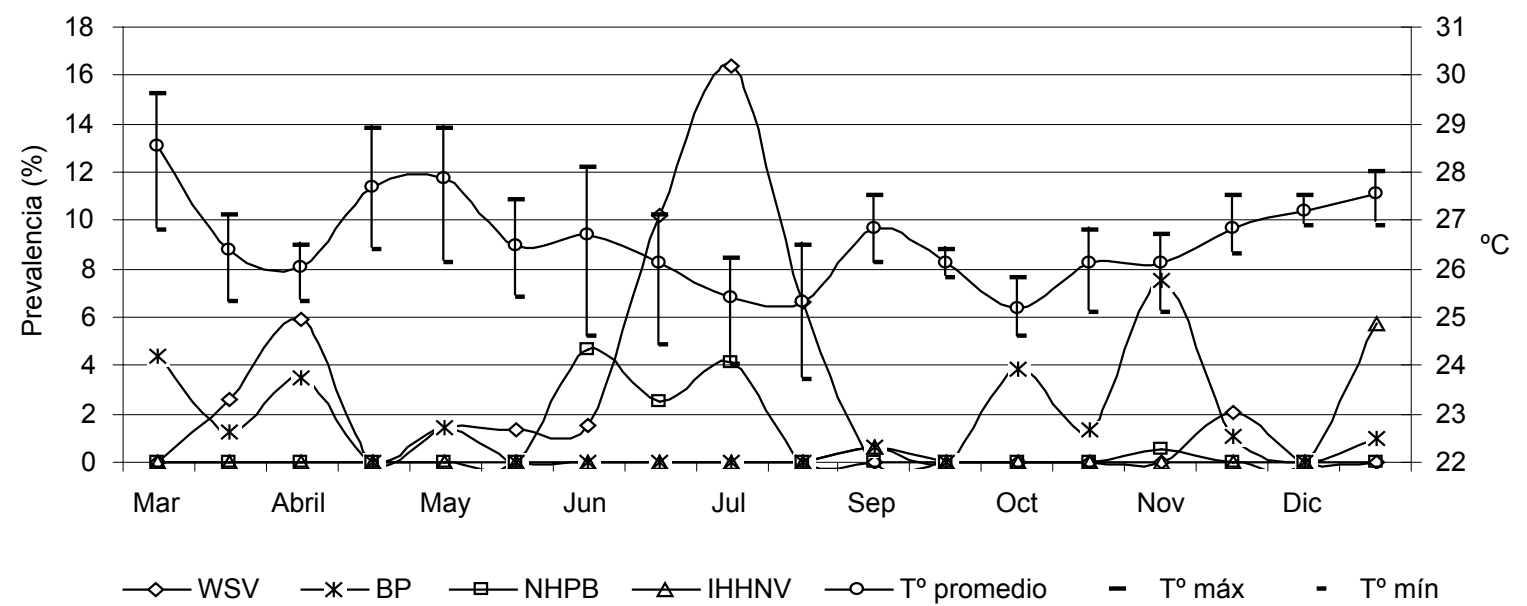

Figura 4. Variación temporal de prevalencias de infección por WSV, BP, NHPB e IHHNV, durante marzo a diciembre de 2009.

infección (Wang et al. 1998, Peng et al. 1998), a diferencia de otros patógenos de langostinos que presentan cierta especificidad de hospederos. Rajendran et al. (1999), manifiestan que un mecanismo esencial para la persistencia de algunos virus, es la existencia de hospederos alternativos y reservorios en diferentes poblaciones de origen silvestre. Estas características explican su amplia distribución en las zonas de muestreo de este estudio.

Valores de prevalencias en diversos langostinos y cangrejos, para WSV fueron de 3,5\%, 11,6\%, 5,2\% y 3,4\% en los años 2001, 2002, 2003 y 2004 respectivamente (IMARPE-Tumbes, datos no publicados), con tendencia a disminuir con el paso del tiempo; para el ańo 2005, la prevalencia reportada para el WSV fue de $3,3 \%$, y de $1,7 \%$ para el 2006, siguiendo la tendencia de años anteriores. Sin embargo; en el 2009 la prevalencia al WSV fue de $2,75 \%$, incremento posiblemente influenciado por el aumento en las densidades de los cultivos de langostinos y la
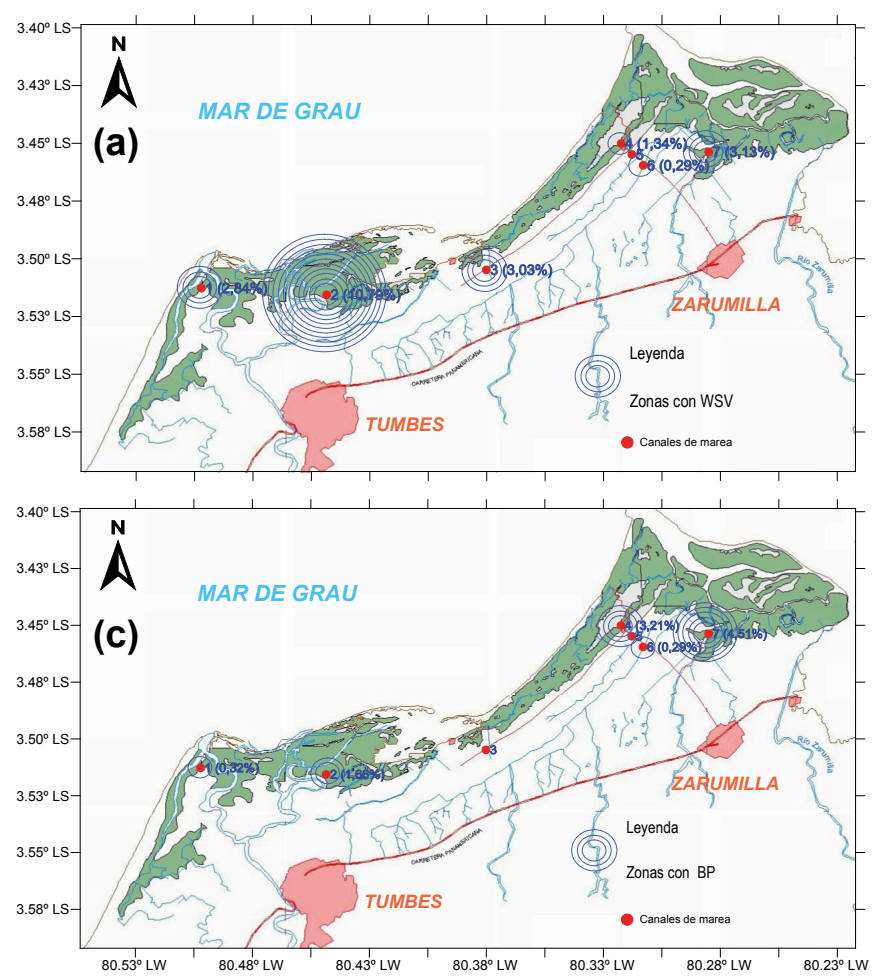

descarga de sus efluentes en los canales de marea monitoreados. Datos de la OIE (2009), indican que las prevalencias de infección por este virus son menores al $1 \%$ en poblaciones silvestres.

La mayor prevalencia $(10,79 \%)$ en el canal de marea El Alcalde ocurre posiblemente por la extensa área de producción en la zona, la inadecuada tecnificación en el manejo de los cultivos por parte de sus cultivadores, y las descargas de desechos sin ningún tratamiento previo, que mantienen a los langostinos silvestres en condición de estrés, haciéndolos más susceptibles a la infección por WSV, resultando en un aumento de la prevalencia, comparado con ańos anteriores.

Para el patógeno BP, los datos muestran prevalencias puntuales desde 0 hasta $5,22 \%$, encontrándose resultados positivos en gran parte del tiempo que duró la investigación. Al parecer la presencia de este patógeno no está condicionada por las variaciones de temperatura, contrario a lo observado con el WSV, cuya
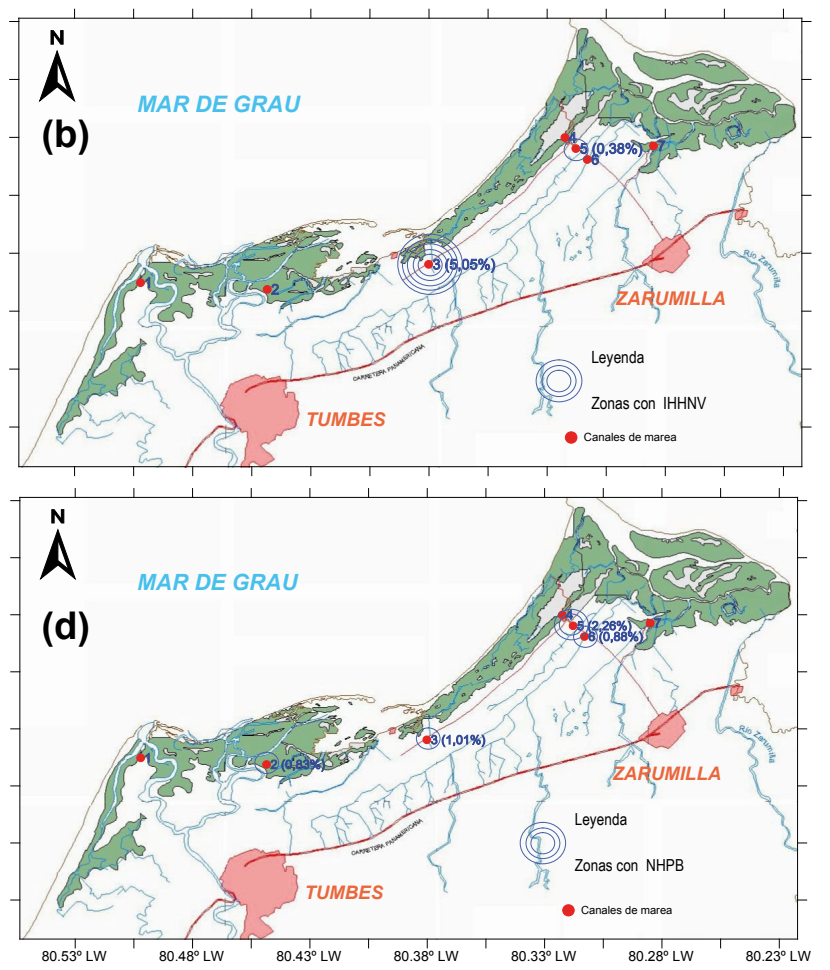

Figura 5. Distribución del (a) WSV, (b) IHHNV, (c) BP y (d) NHPB en canales de marea, durante marzo a diciembre de 2009. Canales de marea: 1. Boca del Río Tumbes 2. El Alcalde 3. Jelí 4. El Bendito 5. Envidia 6. Soledad y 7. Algarrobo. 
presencia estaría modulada por las variaciones de temperatura. Se observa que en la época con menores temperaturas (junio y julio), las prevalencias del WSV aumentan considerablemente (prevalencia máxima 11,28\% en el mes de julio). Observaciones en años anteriores indican el mismo patrón (IMARPE-Tumbes, datos no publicados); concluyendo que la estación de invierno es de alto riesgo y poco apropiado para el cultivo de langostino. Similar relación parece ocurrir con la bacteria de la NHP, que fue reportada en esta época. Lightner (2006) asocia la presencia de este patógeno con los factores ambientales como temperatura (29 a $35^{\circ} \mathrm{C}$ ) y salinidades elevadas (20 a $38 \mathrm{ppt}$ ) durante periodos prolongados; en nuestros resultados la presencia de la NHPB fue mayor en los canales de marea que presentan salinidades más elevadas de la zona (36 a 41 ups), pero en periodos de bajas temperaturas $\left(25 \mathrm{a} 26^{\circ} \mathrm{C}\right)$.

Las prevalencias para el IHHNV durante los meses de marzo a noviembre fluctuaron entre 0 y $0,67 \%$, con una prevalencia global de $0,31 \%$. La prevalencia obtenida en el mes de diciembre $(5,71 \%)$ al parecer estuvo influenciada por escapes accidentales en la cosecha de L. vannamei cultivados e infectados. En esta época, en una empresa langostinera aledaña al canal de marea Jelí, se reportó alta incidencia del IHHNV en sus estanques de cultivo entre los meses de noviembre a diciembre (IMARPETumbes, datos no publicados).

Esta condición significa un riesgo potencial y de carácter letal para la población silvestre de L. stylirostris, altamente susceptible a la infección por el IHHNV. Las prevalencias del IHHNV en langostinos de cultivo intensivo fluctúan entre $4-96 \%$ y en semi-intensivos de $0-100 \%$ (IMARPE-Tumbes, datos no publicados), se pone de manifiesto el peligro potencial de la transmisión de este virus a las poblaciones naturales peneidos si no se cuenta con las medidas de bioseguridad adecuadas, que impidan el escape accidental de langostinos de cultivo.

Aunque no se obtuvo resultados positivos al TSV y debido a su carácter endémico en la región (Lightner 1996), se calculó la prevalencia máxima posible que se podría obtener en la población bajo estudio, la cual fluctuó entre 0 y 0,33\%. Es escasa la información concerniente a la prevalencia de TSV en poblaciones de langostinos silvestres. La OIE (2006), refiere que en regiones de cultivo con presencia endémica de TSV, las prevalencias fluctúan de 0 al 100\%, encontrándose ocasionalmente en L. vannamei silvestres. Según Brock et al. (1997), no existen evidencias que este virus halla impactado a las poblaciones naturales, al parecer se presenta como una enfermedad subclínica en las poblaciones de langostinos silvestres.

Se conoce que los patógenos que se encuentran en muy bajas prevalencias en organismos silvestres, por lo general sin causar enfermedad clínica, pueden dar lugar a altos niveles de prevalencia y mortalidad en organismos en cultivo, debido al elevado nivel de estrés producto de las altas densidades de población y otros factores físicos y químicos que alteran la calidad del agua de cultivo (Raynard et al. 2007).

La presencia de brotes de infección de los patógenos WSV, BP, NHPB e IHHNV en langostinos peneidos de diferentes canales de marea de Tumbes con prevalencias mayores a las de años anteriores, indican un riesgo latente de transmisión de estos patógenos hacia los cultivos de langostinos y también de cierta forma afectar a las poblaciones de las especies más susceptibles de peneidos silvestres de las zonas del manglar, las cuales deben ser protegidas por razones económicas y ecológicas.

\section{Literatura citada}

Brock J.A. 1997. Special topic review: Taura syndrome, a disease important to shrimp farms in the Americas. World J. Microbiol \& Technol. 13: 415-418.

Corbel V., Z. Zuprizal, C. Shi, et al. 2001. Experimental infection of European crustaceans with white spot syndrome virus (WSSV). J. Fish. Dis. 24 (7): 377-382.

Chakraborty A., S. Otta, B. Joseph, et al. 2002. Prevalence of white spot syndrome virus in wild crustaceans along the coast of India. Current Science. 82:1392-1397 pp.

Fajer E., Y. Noriega, D. Menéndez, T. Frías. 1998. Prevalencia de Baculovirus penaei PsSOV Bonami (antes BP) en camarones peneidos cubanos silvestres. Vet. Méx. 29 (2): 209-211 pp.

Gustincich S, Manfiolett G, Del Sal G, Schneider C, Carnici P. 1991. A fast method for high quality genomic DNA extraction from whole human blood. Biotechniques. 11(3): 298-302.

Lien T, Hsiung H, Huang C, Song Y. 2002. Genomic similarity of Taura syndrome virus (TSV) between Taiwan and Western Hemisphere isolates. Fish Pathology. 37(2): 71-75 pp.

Lightner D.V. 1996. A handbook of shrimp pathology and diagnostic procedures for diseases of cultured penaeid shrimp. World Aquaculture Society. Baton Rouge. Louisiana. USA. 304 pp.

Lo C.F., C.H. Ho, S.E. Peng, C.H. Chen, et al. 1996. White spot syndrome baculovirus (WSBV) detected in cultured and captured shrimp, crabs and other arthropods. Dis. Aquat. Org. 27: 215-225.

Loy J.K., P.F. Frelier, P. Varner, J.W. Templeton. 1996. Detection of the etiologic agent of necrotizing hepatopancreatitis in cultured Penaeus vannamei from Texas and Peru by polymerase chain reaction. Diseases of Aquatic Organisms. 25: 117-122.

Morales V. \& J. Cuellar-Anjel. 2008. Guía técnica - Patología e inmunología de camarones peneidos. Programa CYTEC Red II-D Vannamei. Panamá. 270 pp.

Nakano H., H. Koube, S. Umezawa S, F. Momoyama, et al. 1994. Mass mortality of cultured Kuruma shrimp, Penaeus japonicus, in Japan in 1993: epizootiological survey and infection trials. Fish Pathol 29: 135-139.

OIE. 2006. (en línea) Manual de pruebas de diagnóstico para los animales acuáticos. <http://www.oie.int/esp/normes/ fmanual/e_SUMMRY.HTM $>$

Peng S.E., C.F. Lo, C.H. Ho, et al. 1998. Detection of white spot baculovirus (WSBV) in giant freshwater prawn, Machrobrachium rosenbergii, using polymerase chain reaction. Aquaculture. 164: 253-262.

Rajendran K.V., K.K. Vijayan K, T.C. Santiago, R.M. Krol. 1999. Experimental host range and histopathology of white spot syndrome virus (WSSV) infection in shrimp, prawns, crabs and lobsters from India. Journal of Fish Diseases. 22: 183-191.

Raynard R., T. Wahli, I. Vatsos \& S. Mortensen (Eds.) 2007. Review of disease interactions and pathogen exchange between farmed and wild finfish and shellfish in Europe. VESO project number:1655. VESO, Oslo, Norway. 459 pp.

Sánchez-Martínez J.G., G. Aguirre-Guzmán \& H. Mejía-Ruíz. 2007. White Spot Syndrome Virus in cultured shrimp: A review. Aquaculture Research 38(13): 1339-1354.

Wang Y.C., C.F. Lo, P.S. Chang, G.H. Kou. 1998. Experimental infection of white spot baculovirus in some cultured and wild decapods in Taiwan. Aquaculture 164: 221-231. 